\title{
PROCEEDINGS OF THE CAMBRIDGE ENTOMOLOGICAL CLUB.
}

At the meeting November 9th, Mr. L. R. Reynolds spoke of his insect collecting around the City of Mexico, where he spent the last winter. Many of the insects were similar to those of Arizona and southern California, but with them were others of more tropical kinds, as the Heliconid butterflies, which came in large numbers to the garden flowers. Many flying insects were caught in the evening by holding a fine net from a moving street-car. A large beetle larva from cactus is sold in the markets for food. Mr. Reynolds met several local entomologists and visited the collection at the National Museum.

Mr. C. W. Johnson told of a visit last summer to Mt. Desert on the coast of Maine, where he took part in the preparation of a catalogue of the animals of the island. Thus far about 1,400 species of insects have been found at Mt. Desert.

At the meeting of December 14th, Prof. C. T. Brues read a paper on microörganisms living within the bodies of Coccidæ, on which he and Dr. Glaser have lately made some new observations. Some can be cultivated in suitable media outside the body of the insect. Experiments suggest that the growth of these plants modifies the fluids around them in such a way as to promote the digestion of plant juices eaten by the insect and to aid in the rapid changes

Mr. J. H. Emerton spoke of the unusually small amount of which take place during the growth of the eggs.

flying of spiders during the autumn just passed, although there was much pleasant weather.

Mr. T. R. Reynolds demonstrated a method which he uses for mounting small Coleoptera between two pieces of thin glass. 

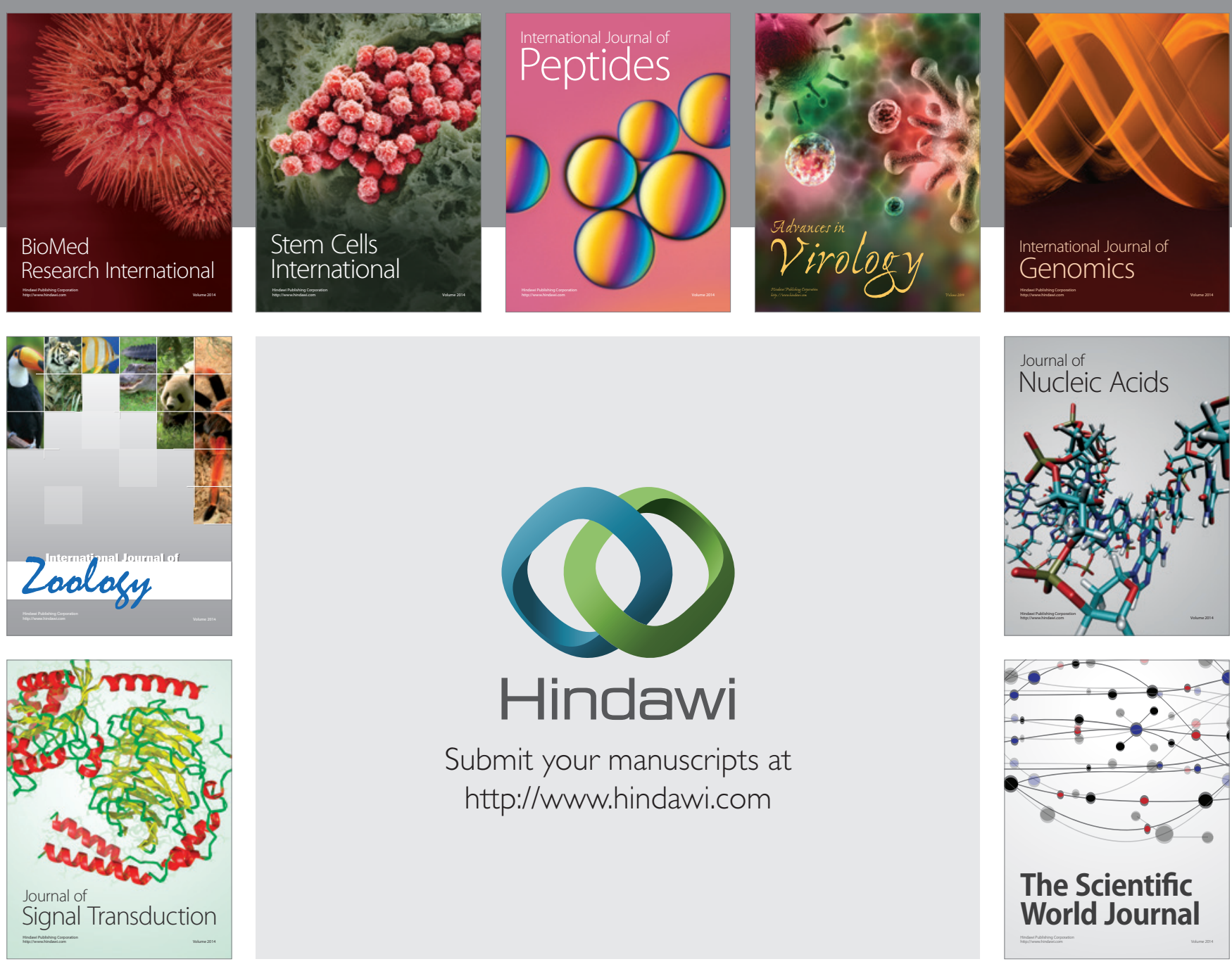

Submit your manuscripts at

http://www.hindawi.com
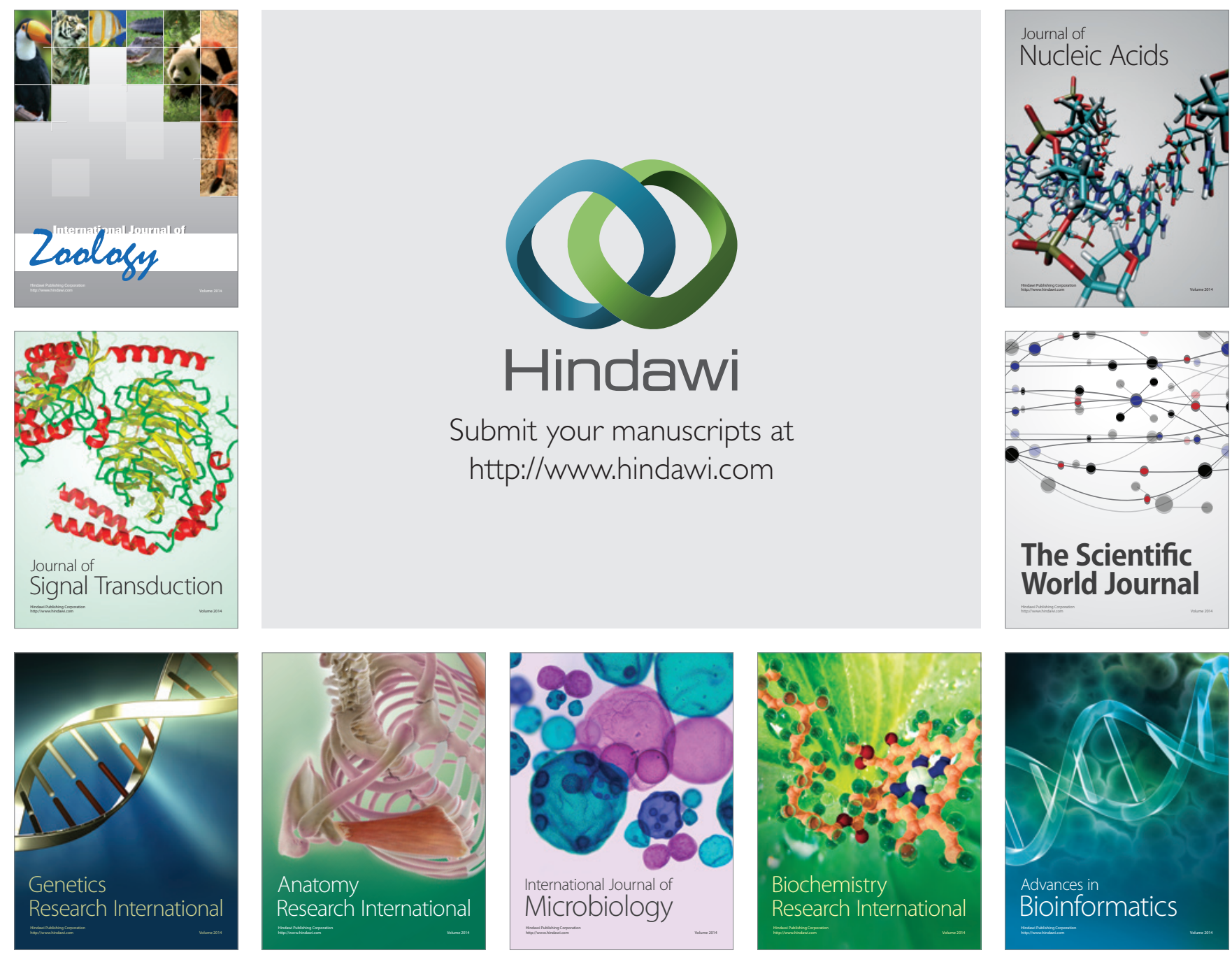

The Scientific World Journal
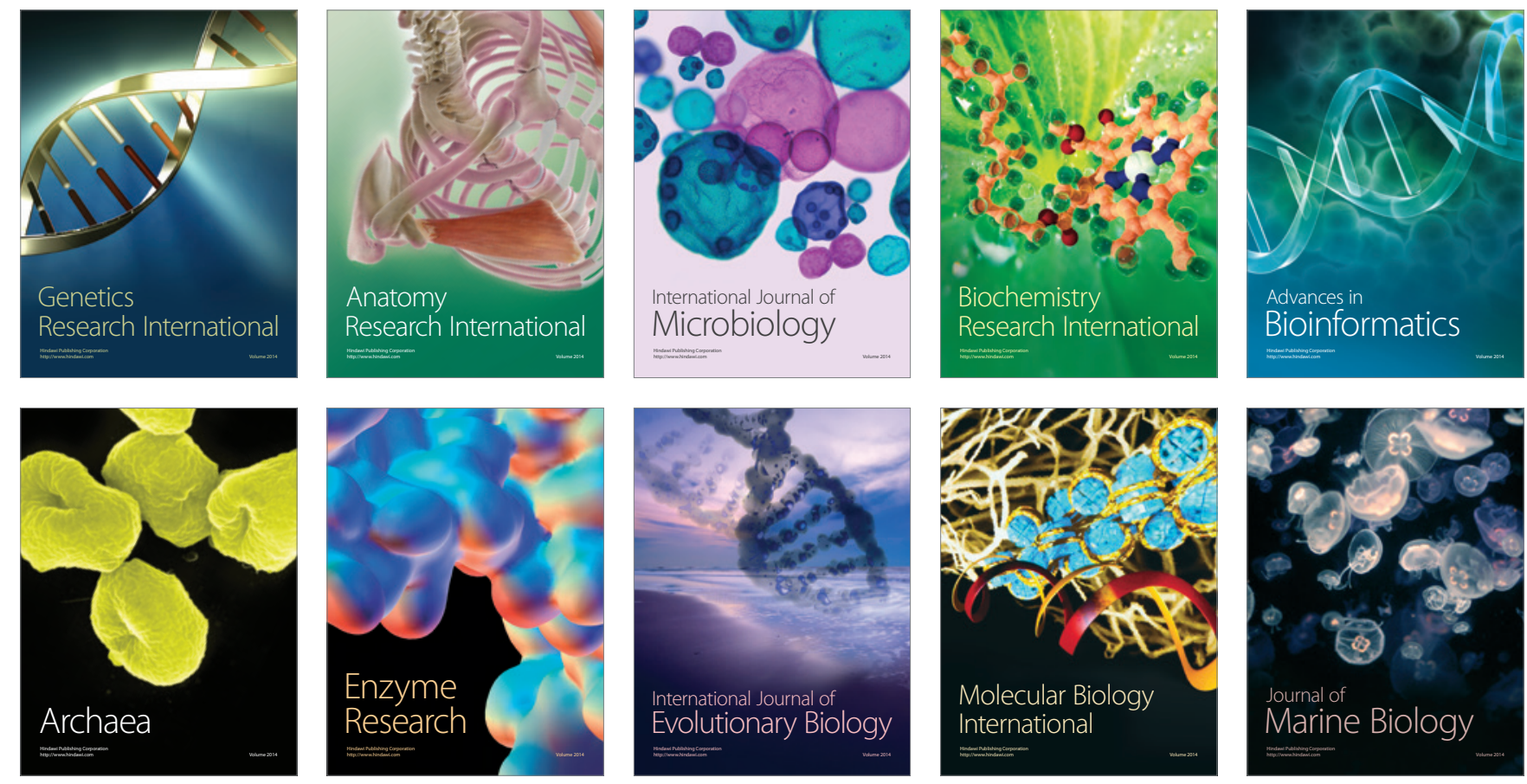